\title{
Renal Vein Thrombosis: An unusual and Initial Manifestation of SLE
}

\author{
Maryam Masoumi, ${ }^{1}{ }^{*}$, Shokoufeh Mousavi ${ }^{2}$ and Zahra Mohammadi ${ }^{1}$ \\ ${ }^{1}$ Department of Internal Medicine, professor of Rheumatology, Qom University of Medical Sciences, Qom, Iran \\ ${ }^{2}$ Department of Internal Medicine, Faculty of Medicine, Qom University of Medical Sciences, Qom, Iran \\ ${ }^{3}$ Research Center, Tehran University of Medical Science, Iran
}

Submission: August 31, 2018; Published: October 17, 2018

*Corresponding author: Maryam Masoumi, Department of Internal Medicine, professor of Rheumatology, Qom University of Medical Sciences, Qom, Iran, Email: m.masoumiy@gmail.com

\begin{abstract}
Although there is a strong connection between the Systemic lupus erythematosus (SLE) and clotting formation, SLE with initial manifestations of Renal Vein Thrombosis is rare. Thrombosis of the renal vein (RVT) has been observed in patients with various types of APS, such as aPlpositive patients with lupus nephritis. This is a case of a 30-year-old man admitted to the Emergency Room (ER) because of mild hemoptysis and transient hematuria for 9 days. He had experienced right quadrant abdominal pain, right flank pain, and fever for 40 days before admission. Due to pain, the patient underwent an appendectomy but did not recover and pathological examination and clinical picture led to a diagnosis of SLE. In general, the mainstay of treatment for RVT is anticoagulation. He was medical treatment with anticoagulation and corticosteroid and cytotoxic drugs. So abdominal and flank pain could be an initial and unspecific symptom in RVT for patients with SLE.
\end{abstract}

Keywords: Systemic lupus erythematosus (SLE); Renal Vein Thrombosis; Lupus Nephritis (LN)

\section{Introduction}

Predominantly, the initial presentation of SLE is arthritis, rash, and fever [1]. Although there is a strong connection between the SLE and clotting formation [2], renal vein thrombosis is a renal vascular complication of SLE but it is very rare. There is three thrombotic vascular syndromes relationship to SLE, including: renal vein thrombosis, thrombotic thrombocytopenic purpura (TTP) like syndrome and the antiphospholipid syndrome $[3,4]$. Herein, we report a case of a male patient who initially demonstrated manifestations of flank pain and fever that led us to a diagnosis of SLE finally.

\section{Case Report}

A 30-year-old man admitted to the Emergency Room (ER) due to mild hemoptysis and transient hematuria started from 9 days before. He had also severe right-sided pleuritic chest pain, cough, lower right quadrant abdominal pain, chill, and fever. 40 days earlier, he had admitted to elsewhere because of such an episode of right flank pain and fever. And at that time, surgeon believed this is a presentation of appendicitis so appendectomy performed; but the pain of the patient continued and had not recovered. In addition, he had a right shoulder joint pain for the last two month. Past medical history was left renal stone and asthma. The patient had received spray salbutamol PRN for his asthma.
On physical examination, his blood pressure was 126/86 $\mathrm{mmHg}$, pulse rate $99 / \mathrm{min}$, respiratory rate $20 / \mathrm{min}$, body temperature $38.5 \mathrm{C}$ and saturation 02 in air room $95 \%$. He had no rash, oral ulcer, oral aphthosis ulcer and photosensitivity. Decreased breath sounds heard on auscultation of right lung. All examination of other systems proved normal. Laboratory evaluation disseminate serum urea $24 \mathrm{mg} / \mathrm{dl}$, creatinine $1.8 \mathrm{mg} /$ $\mathrm{dL}$, serum albumin $4.0 \mathrm{~g} / \mathrm{dL}$ (3.6-4.8), erythrocyte sedimentation rate (ESR) $92 \mathrm{~mm} / \mathrm{h}$, C-reactive protein (CRP) level of $176 \mathrm{mg} /$ $\mathrm{dl}(>15 \mathrm{mg} / \mathrm{dl}$ ),, hemoglobin $11.0 \mathrm{~g} / \mathrm{dl}$, mean corpuscular volume (MCV) $79 \mathrm{fl}$, white blood cell count $6.3 \mathrm{~K} / \mathrm{uL}$, and platelets 277 $\mathrm{K} / \mathrm{uL}$.

Other hematological and biochemical parameters were normal. Urine test results revealed proteinuria +3 without hematuria and pyuria. Urine microscopy was normal. 24-hour protein excretion was $2607 \mathrm{mg}$ (urine protein/ creatinine ratio was $2.2 \mathrm{mg} / \mathrm{mg}$ ). HIV, Hbs Ag, anti-Hbs, anti-Hbe, and anti-HCV were all negative. At that time, anti-ds stranded DNA (anti-dsDNA) >800 (>100), F-ANA (titer: 1:640, Homogenous pattern), lupus anticoagulant and $\beta 2 \mathrm{GPI} \operatorname{IgG}(>3 \mathrm{ULN})$ tests were positive. He tested negative for Anticardiolipin Ab (ACL), Anti Neutrophil Cytoplasmic Ab (ANCA) and RF. His complement C3, C4, and CH50 levels were normal. VDRL was nonreactive, protein $\mathrm{C}$ and $\mathrm{S}$ and antithrombin III and factor V Leiden were normal. 




Figure 1: A chest radiography did show bilateral flating and elevation of the diaphragms, significant hypoinflation as demonstrated by visualization of 6 posterior ribs. The radiographs demonstrate left lower lobe atelectasis.

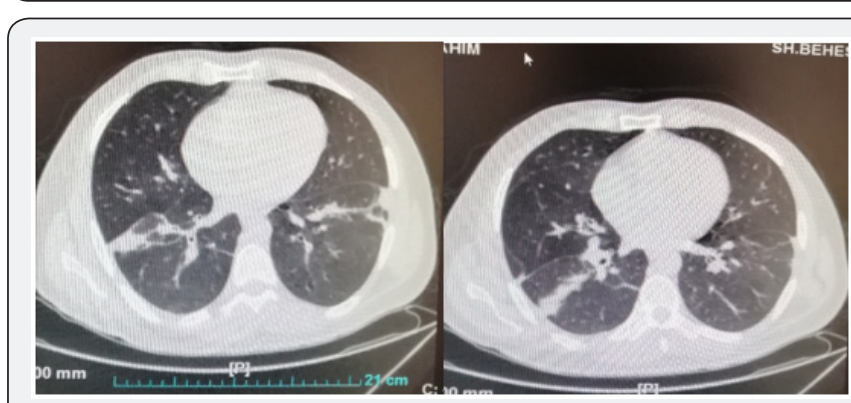

Figure 2: Computed tomography (CT) of the lung revealed multiple variable sized nodules.

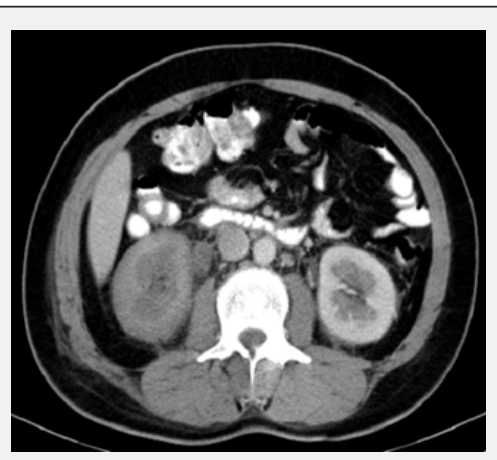

Figure 3: Spiral CT scan of the abdominopelvis with IV and oral contrast noted intraluminal defect in right renal vein and IVC in favour of thrombosis.

Chest radiography did show bilateral flatting and elevation of the diaphragms and significant hypo inflation as demonstrated by visualization of 6 posterior ribs. The radiographs demonstrate left lower lobe atelectasis (Figure 1). Ultrasound of the abdomen showed slight enlargement of kidneys (right kidney 135 mm, left kidney 140 mm). Computed tomography (CT) of the lung revealed multiple variable sized nodules (Figure 2). Spiral CT scan of abdominopelvic with IV and oral contrast noted intraluminal defect in right renal vein and IVC in favor of thrombosis (Figure 3). The abdominal aorta and its branches in particular renal arteries appear normal in contrast abdominal CT angiography but inferior vena cava (IVC) right renal artery revealed filling defect can be a suggestion for RVT. A contrast-enhanced CT angiography of pulmonary artery revealed multifocal intraluminal filling defects in most of both lower lobe segmental and subsegmental branches, that favor of thromboembolism (Figure 4).

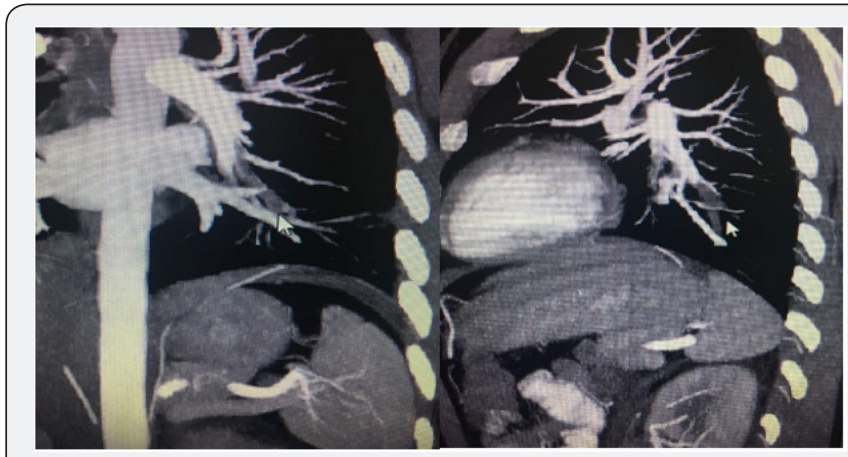

Figure 4: A contrast- enhanced CT angiography of pulmonary artery revealed multifocal intraluminal filling defects in most of both lower lobe segmental and subsegmental branches, that favour of thromboembolism.

The diagnosis of SLE is based on Systematic Lupus International Collaborating Clinic Criteria (SLICC). He satisfied 7 of the 11 criteria: Arthritis, Serositis, Lupus Nephritis, positive for a lupus anticoagulant and FANA and anti-ds-DNA and low complement and $\beta 2 \mathrm{GPI} \operatorname{IgG}(>3 \mathrm{ULN})$ tests were positive. A renal biopsy supported Lupus nephritis (WHO class IV) as the reason of proteinuria. This is an unusual manifestation of SLE which presented in renal vein thrombosis is the result of having antiphospholipid antibodies in his serum that mistaken as an appendix and this is an important point in this case. The pathologic finding of the appendix sample demonstrated mild inflammation, immune-allergic type submucosal small vessel involvement, appendix (seen in SLE).

He received low molecular weight heparin (LMWH) (enoxaparin $60 \mathrm{mg}$ every $12 \mathrm{~h}$ subcutaneous) a followed by Warfarin $10 \mathrm{mg} / \mathrm{d}$ but the patient had a complication of gastrointestinal bleeding after one month of starting this treatment. Endoscopy of the upper gastrointestinal noted oozing ulcer and we restarted Warfarin inpatient in caution and the patient had no problem with this treatment. For the treatment of lupus, Endoxan ( $1 \mathrm{gr}$ ) and prednisolone (1 gr puls $\times 3 \mathrm{~d}$ then 0.5 $\mathrm{mg} / \mathrm{kg} / \mathrm{d}$ ) and prednisolone taper till $7.5 \mathrm{mg}$ while the patient was under control and we also treat him 6 andoxan puls and after that we switched to Cellcept $2 \mathrm{~g} / \mathrm{D}$ and he was recovered totally and go back to his work.

\section{Discussion}

Renal vein thrombosis (RVT) in a lupus patient was first reported in 1968 [3]. SLE patients with the antiphospholipid antibodies, nephrotic syndrome and prior episodes of thrombophlebitis have a higher incidence of RVT [5]. but it may also association in a variety of conditions: sickle cell anemia [6] malignancy [7] severe dehydration [8] homocystinuria [8] trauma [4]. The frequency of RVT shown 5 - $62 \%$ in literary texts $[9,10]$. Almost association SLE with APS is $35-40 \%$. Combination 
of SLE and APS will develop thrombotic events and spontaneous RVT $[4,11]$. Coupled with SLE and membranous nephropathy are in relation with RVT [12].

SLE has been changed blood coagulation factors [13]. A very strong dependency among the clotting defect and lupus anticoagulant was noted [2]. Antiphospholipid syndrome is a common cause of hypercoagulable in patients with RVT $[1,14]$, but the main cause of RVT in SLE patients is nephrotic syndrome(4). Gregorio Mintz et al. [9] suggested, SLE association with thrombophlebitis had a high risk of developing IVCT or RVT [8]. Several mechanisms activated the coagulability in SLE patient, including: the imbalance between antithrombotic and prothrombotic factors and increased platelet aggregation $[1,2,15]$. Kauffmann et al. [16] investigated serum antithrombin III levels and its relation to the incidence of thromboembolic phenomena for 48 patients with proteinuria. thromboembolic evidence was detected in 9 of 48 patients but only 4 of 9 with renal vein thrombosis and 8 of 9 patients, blood antithrombin III levels were under 70 percent of normal [17]. In confirmation, our patient had SLE and APS syndrome that let to RVT without any past history. Therefore ethnic difference should not be forgotten.

Mostly, prompt and accurate diagnosis needed a high index of suspicion. An imaging remains the cornerstone in ruling out RVT [16]. Radiological assessments can detect in acute RVT which is distinguished by renal enlargement and hyperechogenicity nearly $90 \%$ of the patients at the early phase [18-21]. CT angiography has been acquired popularity in diagnosing RVT for the patient because of its high sensitivity and non-invasive. Approximately the specificity and sensitivity of CT angiography is 100 percent [4].

During the acute phase of clinical manifestation, with lumbar or flank pain could be confused with other more frequent cases such as renal or urethral lithiasis, pyelonephritis, renal cancer, or other retroperitoneal or intraabdominal inflammatory situation. The collection of the right-sided pleuritic pain, hemoptysis, and right quadrant abdominal pain with a proteinuria in the absence of acute kidney injury suggested the kidney involvement. In such a case, ruling out acute renal vein thrombosis is critical. A diagnosis of IVCT or RVT should be considered because SLE is a varying disease that could present itself in many other organ systems, clinicians should be conscious of such a disease especially young patient.

\section{Conflict of Interest}

No.

\section{References}

1. Onishi S, Ichiba T, Nagata T, Naito H (2016) Unusual initial presentation of SLE: fever and flank pain with renal vein thrombosis. The American journal of emergency medicine. 34(5): 937. e1-e2.

2. Boey M, Colaco C, Gharavi A, Elkon K, Loizou S, (1983) Thrombosis in systemic lupus erythematosus: striking association with the presence of circulating lupus anticoagulant. Br Med J (Clin Res Ed) 287(6398): 1021-1023.

3. Appel G, Pirani C, D’ Agati V (1994) Renal vascular complications of systemic lupus erythematosus. Journal of the American Society of Nephrology 4(8): 1499-515.

4. Yenigün Eç, Dede F, Pişkinpaşa Sv, Öztürk R, Özkayar N, et al. (2014) Systemic Lupus Erythematosus Presenting with Renal Vein Thrombosis: A Case Report. Turkish Nephrology, Dialysis and Transplantation 23(2): 172-174.

5. Kirby JM, Jhaveri KS, Maizlin ZV, Midia M, Haider E, et al. (2009) Abdominal manifestations of systemic lupus erythematosus: spectrum of imaging findings. Canadian Association of Radiologists Journal 60(3): 121-132.

6. Appel GB, Williams GS, Meltzer JI, Pirani CL (1976) Renal vein thrombosis, nephrotic syndrome, and systemic lupus erythematosus: an association in four cases. Ann Intern Med 85(3): 310-317.

7. Strom T, Muehrcke RC, Smith RD (1972) Sickle cell anemia with the nephrotic syndrome and renal vein obstruction. JAMA internal medicine 129(1): 104-108.

8. De Swiet J, Wells A (1957) Nephrotic syndrome associated with renal venous thrombosis and bronchial carcinoma. Br Med J 1(5031): 13411343.

9. Mintz G, Acevedo-Vázquez E, Gutiérrez-Espinosa G, Avelar-Garnica F (1984) Renal vein thrombosis and inferior vena cava thrombosis in systemic lupus erythematosus. Arthritis Rheum 27(5): 539-544.

10. Brenner B (2004) Disorders of renal arteries and veins. The kidney $7^{\text {th }}$ ed Pennsylvania, Saunders, USA, 1584.

11. Hidas G, Chervinsky L, Rozenman Y, Zelichtnko G, Shental Y (2006) Renal vein thrombosis--renal colic with unusual course. Harefuah 145(8): 597-600.

12. Ruiz-Irastorza G, Crowther M, Branch W, Khamashta MA (2010) Antiphospholipid syndrome. The Lancet 376(9751): 1498-1509.

13. Ma AL-t, Lai W-m, Chiu M-c (2010) An unusual case of loin pain and nephritis. Clinical and experimental nephrology 14(1): 75-79.

14. Chen X, Xu G (2018) Intravenous thrombolysis in SLE-related stroke: a case report and literature review. Neurol Sci 39(1): 155-159.

15. Llach F, Papper S, Massry SG (1980) The clinical spectrum of renal vein thrombosis: acute and chronic. The American Journal of Medicine 69(6): 819-827.

16. Kauffmann RH, Veltkamp JJ, Van Tilburg NH, Van Es LA (1978) Acquired antithrombin III deficiency and thrombosis in the nephrotic syndrome. The American journal of medicine 65(4): 607-613.

17. Margolius Jr A, Jackson DP, Ratnoff OD (1961) Circulating anticoagulants: a study of 40 cases and a review of the literature. Medicine 40(2): 145-202.

18. Brandão LR, Simpson EA, Lau KK (2011) Neonatal renal vein thrombosis. Seminars in fetal and neonatal medicine 16(6): 323-328.

19. Asherson R, Buchanan N, Baguley E, Hughes G (1993) Postpartum bilateral renal vein thrombosis in the primary antiphospholipid syndrome. The Journal of Rheumatology 20(5): 874-876.

20. Fishman J, Joseph R (1994) Renal vein thrombosis in utero: duplex sonography in diagnosis and follow-up. Pediatric radiology 24(2): 135-136.

21. Lau KK, y Garcia EF, Kwan WY, Albrecht L, Stein-Wexler R (2007) Bilateral renal venous thrombosis and adrenal hemorrhage: sequential prenatal US with postnatal recovery. Pediatric Radiology 37(9): 912925. 
CC This work is licensed under Creative CC Commons Attribution 4.0 License BY DOI: 10.19080/OROAJ.2018.13.555854
Your next submission with Juniper Publishers will reach you the below assets

- Quality Editorial service

- Swift Peer Review

- Reprints availability

- E-prints Service

- Manuscript Podcast for convenient understanding

- Global attainment for your research

- Manuscript accessibility in different formats

( Pdf, E-pub, Full Text, Audio)

- Unceasing customer service

Track the below URL for one-step submission https://juniperpublishers.com/online-submission.php 